\title{
Article
}

\section{Water-Induced Reordering in Ultrathin Ionic Liquid Films}

Henderson, Zoe, Walton, Alex, Thomas, Andrew G and Syres, Karen Available at http://clok.uclan.ac.uk/23626/

Henderson, Zoe, Walton, Alex, Thomas, Andrew G and Syres, Karen ORCID: 0000-0001-7439-475X (2018) Water-Induced Reordering in Ultrathin Ionic Liquid Films. Journal of Physics: Condensed Matter, 30 (33). ISSN 0953-8984

It is advisable to refer to the publisher's version if you intend to cite from the work. http://dx.doi.org/10.1088/1361-648X/aad24f

For more information about UCLan's research in this area go to

http://www.uclan.ac.uk/researchgroups/ and search for <name of research Group>.

For information about Research generally at UCLan please go to http://www.uclan.ac.uk/research/

All outputs in CLoK are protected by Intellectual Property Rights law, including Copyright law. Copyright, IPR and Moral Rights for the works on this site are retained by the individual authors and/or other copyright owners. Terms and conditions for use of this material are defined in the policies page.

\section{CLoK}

Central Lancashire online Knowledge www.clok.uclan.ac.uk

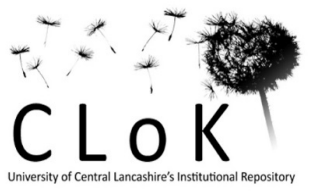




\title{
Water-Induced Reordering in Ultrathin Ionic Liquid Films
}

\author{
Z. Henderson a, A. S. Walton ${ }^{b}$, A. G. Thomas ${ }^{c}$, K. L. Syres ${ }^{a *}$ \\ aJeremiah Horrocks Institute, University of Central Lancashire, Preston, United Kingdom, PR1 \\ $2 H E$ \\ ${ }^{\mathrm{b} S}$ School of Chemistry, and 'School of Materials, Photon Science Institute, University of \\ Manchester, United Kingdom, M13 9PY
}

\section{Abstract}

Water-induced reordering in ultrathin ionic liquid films has been observed using in situ X-ray photoelectron spectroscopy. An ultrathin layer of 1-butyl-3-methylimidazolium tetrafluoroborate $\left(\left[\mathrm{C}_{4} \mathrm{C}_{1} \mathrm{Im}\right]\left[\mathrm{BF}_{4}\right]\right)$ was deposited on a rutile $\mathrm{TiO}_{2}(110)$ single crystal and exposed to water vapour at a relative humidity of $\sim 70 \%$ in an in situ cell. Water was found to adsorb onto the ionic liquid surface, causing a reordering of the ions at the interface. Water initially remained trapped on the ionic liquid surface as the in situ cell was evacuated. This could have negative implications for supported ionic liquid phase catalysis, where reactants and products move in and out of an ionic liquid containing the catalyst. This insight into the behaviour at the water/ionic liquid interface provides a basis for understanding interfacial behaviour in more complex gas/ionic liquid systems.

\section{Key Words}

X-ray photoelectron spectroscopy, in situ, ionic liquid, ultrathin films, gas capture, water

\section{$\underline{\text { Introduction }}$}

Ionic liquids (ILS) are salts that are liquid at or around room temperature, and they possess a wide variety of unique and interesting properties. As such, they are being investigated for numerous applications, such as lubrication [1,2], corrosion protection and $\mathrm{CO}_{2}$ capture and storage [3-5]. ILs are also being studied for catalysis applications, as their natural ionic state and their characteristic non-volatility make ILs promising alternative solvents for homogeneous catalysis $[6,7]$. In fact, ILs are an integral part of two catalysis concepts: 
Supported Ionic Liquid Phase (SILP) and Solid Catalyst with lonic Liquid Layer (SCILL) [8, 9]. In SILP catalysis, a thin layer of IL containing the catalyst is spread over an inert support material that is high-area and porous [10]. SCILL is similar, but the catalyst is either a solid material, or is immobilised on the support material [11]. The reactions between the catalyst and the gaseous reactants and products take place near the IL/gas interface, so the thin film provides the necessary environment and minimises wastage of both the IL and the catalyst. SCILL and SILP catalysis are therefore attractive due to their cost-effectiveness.

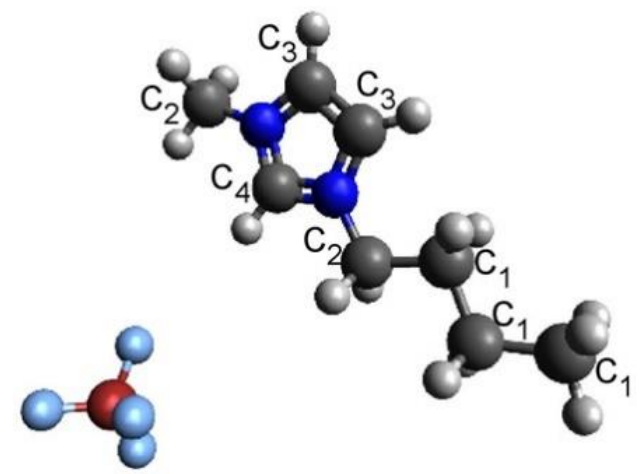

Figure 1. Ball-and-stick diagram of the structure of $\left[C_{4} C_{1} I m\right]\left[B F_{4}\right]$. Grey spheres are carbon atoms, dark blue spheres are nitrogen atoms, light blue spheres are fluorine atoms and the red sphere is a boron atom.

ILs are more structured than most molecular liquids, and their ordering and structure is governed by the structure of their constituent ions. Interactions, and subsequent structure and ordering, at the IL/substrate interface have been investigated previously using ultrathin IL films. A study by Cremer et al [12] showed that imidazolium-based ILs display a different morphology at sub-monolayer coverages on $\mathrm{Ni}(111)$ compared to O-precovered $\mathrm{Ni}(111)$ (specifically $\mathrm{Ni}(111)$ with an $\mathrm{O}(\sqrt{ } 3 \times \sqrt{ } 3) R 30^{\circ}$ superstructure). They observed that on $\mathrm{O}$ precovered $\mathrm{Ni}$, the cation and anion were both in direct contact with the substrate, arranged in a checkboard arrangement. However, on $\mathrm{Ni}$ (111) the ILs demonstrated a bilayer-type ordering, with only the cation in direct contact with the substrate and the anion sat on top of the imidazolium ring of the cation. The arrangement of the IL on the Ni surface was quite different to that observed for the same IL on Au (111) at similar coverages, which instead arranged in a checkerboard formation [8]. Cremer et al also observed that the IL tended to couple more strongly to the metallic Ni surface than the O-covered $\mathrm{Ni}$ surface. 
At the IL/vacuum interface, it has been seen in imidazolium-based ILs that the ions order such that the alkyl chains of the cations face out toward vacuum [13-16], creating a charged under-layer that contains the anions and the imidazolium ring of the cations. It is this ordering that is believed to govern the gas adsorption and uptake by ionic liquids $[17,18]$ including that of water vapour. One obstacle that has yet to be overcome for the use of ILS in industrial applications is their tendency for water capture and uptake. Water has been shown to affect the physical properties of ILs [19-21], so this hygroscopic behaviour is often problematic. Many of their potential industrial applications will be subject to ambient conditions and thus will be, naturally, subject to water vapour. While the effect of water on the bulk properties of ILs has been studied relatively extensively, there have been few studies into the IL/water interface. There are two key concepts associated with the interface that still have yet to be understood: transport of water molecules on and through the surface, and the influence of water on IL surface structure. Understanding the mechanics of water ad/absorption at the IL/water interface is not only vital for a first model of gas capture in ILs, it is also important to understand the implications the addition of water creates for IL thin film applications in ambient conditions.

In order to observe the IL/water interface in a more realistic environment, in situ measurements with high surface sensitivity must be taken. The emergence of near-ambient pressure X-ray photoelectron spectroscopy (NAPXPS) facilities allows the IL/water interface to be studied with the necessary surface sensitivity under more realistic conditions. Here we report on in situ XPS measurements of water with an ultrathin film of the water-miscible IL, 1-butyl-3-methylimidazolium tetrafluoroborate, or $\left[\mathrm{C}_{4} \mathrm{C}_{1} \mathrm{Im}\right]\left[\mathrm{BF}_{4}\right]$ (its structure is shown in Figure 1).

\section{Experimental Section}

The IL, $\left[\mathrm{C}_{4} \mathrm{C}_{1} \mid \mathrm{m}\right]\left[\mathrm{BF}_{4}\right]$ (>97\%, Sigma Aldrich), was degassed in a modified Knudsen cell by heating to $393 \mathrm{~K}$ for three hours to remove water and other impurities. The substrate, a rutile $\mathrm{TiO}_{2}$ (110) single crystal (PI-KEM), was cleaned via $\mathrm{Ar}^{+}$sputter/anneal cycles until the preliminary ultra-high vacuum (UHV) XP spectra showed no contamination. The IL was then heated to $460 \mathrm{~K}$ for vapour deposition onto the room temperature rutile $\mathrm{TiO}_{2}$ substrate for approximately 30 minutes under UHV conditions. The ultrathin deposition of IL was then transferred to the in situ cell, and exposed to water vapour at a pressure of 7 mbar and a 
temperature of $283 \mathrm{~K}$ (relative humidity of $\sim 70 \%$ ). Measurements were taken on a SPECS near-ambient pressure X-ray photoelectron spectroscopy (NAPXPS) system in three regimes: one before water exposure, one during water exposure and one after water exposure. Three measurements were taken during the regime after water exposure (named Pump Stage 1, 2 and 3; shortened to PS 1, PS 2 and PS 3 in Figures 2 and 3), while only one was taken in the other regimes. Each measurement took approximately one hour, and each of the measurements after water exposure were separated by one hour. PS 1 was immediately after water vapour was closed off, and the in situ cell was opened to pumping. PS 2 was approximately two hours after pumping began, and PS 3 was approximately four hours after pumping began. Using the intensity of the $O 1 s$ peak associated with the lattice $O$ in the $\mathrm{TiO}_{2}$, we calculated the thickness of IL to be $(10 \pm 1) \AA$, which corresponds to approximately three IL layers (calculation based on Beer-Lambert law- see SI for full calculation). One of the advantages of using an ultrathin film in this case allowed the IL/water interface to be observed directly without the need for more surface-sensitive grazing emission XP spectra (which is not possible on the NAPXPS system used for these measurements).

All spectra are the result of merged raster scans (short scans taken at equally spaced points, specifically $0.6 \mathrm{~mm}$ part in a $6 \times 5$ grid on the sample, then merged), taken as such to reduce beam damage effects. A small-scale investigation was conducted into beam damage on the system studied, which is featured in the SI. In each regime, scans of the $C 1 s, O 1 s, N$ is and $\mathrm{F}$ 1s regions were recorded, all at normal emission. The binding energies were referenced to the $C$ 1s component that corresponds to the alkyl chain of the IL cation at $285.5 \mathrm{eV} \mathrm{[22]} \mathrm{and}$ quoted to $\pm 0.1 \mathrm{eV}$. All spectra were fitted with a Shirley background and 30:70 (Gaussian:Lorentzian) Voigt line shapes in the absence of sample charging or analyser artefacts. Peak fitting was performed using CasaXPS software.

\section{Results and Discussion}



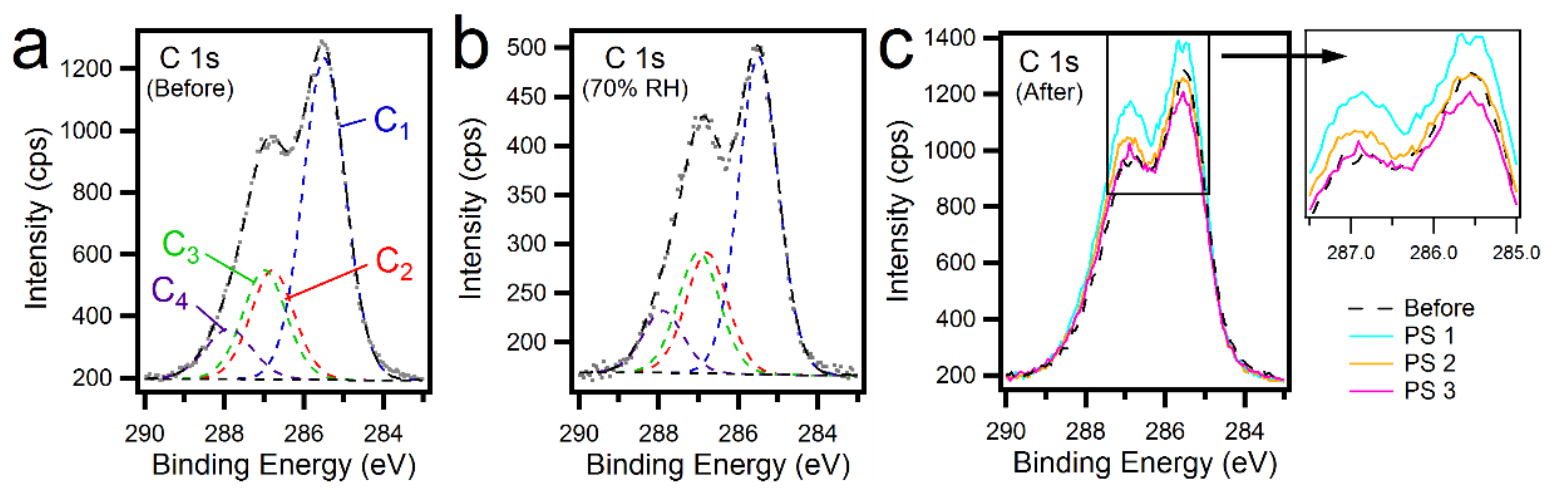

Figure 2. (a) $C 1$ s spectrum before exposure to water, (b) $C 1$ s spectrum at $70 \% R H$, and (c) $C$ 1s spectrum from PS 1 to PS 3, together with the pre-water $C 1$ s spectrum.

Figure 2(a) shows the $\mathrm{C} 1 \mathrm{~s}$ spectrum for the sample prior to water exposure. It can be fitted with four composite peaks, (corresponding to the numbered carbon atoms in Figure 1) and in good agreement with literature [22]. The peak at $285.5 \mathrm{eV}$ corresponds to that of the alkyl chain carbons, labelled $C_{1}$ in Figure 1 . The peak at $286.8 \mathrm{eV}$ corresponds to the $C_{2}$ carbons just outside of the imidazolium ring, the peak at $287.0 \mathrm{eV}$ corresponds to the $\mathrm{C}_{3}$ carbons inside the imidazolium ring and the peak at $287.9 \mathrm{eV}$ corresponds to the $\mathrm{C}_{4}$ carbon, between the two $\mathrm{N}$ atoms in the imidazolium ring (binding energies and the assignments of these peaks are included in Table 1). The alkyl carbon peak and the imidazolium carbon peaks together create the characteristic two-peak shape of the $C 1 s$ region. A study by Wagstaffe et al [22] of multilayer and approximately monolayer coverages of $\left[\mathrm{C}_{4} \mathrm{C}_{1} \mid \mathrm{m}\right]\left[\mathrm{BF}_{4}\right]$ on anatase $\mathrm{TiO}_{2}$ (101) highlighted distinct differences between the $\mathrm{C} 1 \mathrm{~s}$ regions of the bulk and monolayer IL films. More specifically, the component associated with the alkyl chain and two of the three components associated with the imidazolium group were found to shift to a lower binding energy (BE) for the thin film. This observation is consistent with findings reported by Cremer et al with analogous ILs [8]. As expected, the binding energies of the components of the $C 1$ s region in our study are more in line with those of a thin film. However, the alkyl chain component dominates the region, which is not consistent with the shape of the $C 1$ s observed by Wagstaffe et al. The film studied here is indeed thicker than the monolayer film studied by Wagstaffe et al, and while it is known that alkyl chains face outward toward vacuum in imidazolium-based ILs, the strength of the alkyl chain signal here may be explained by a contribution from carbon contamination. 
ILs have a tendency to become contaminated via external sources: such as the introduction of adventitious carbon from exposure to atmosphere $[23,24]$, or even Si contamination due to grease present in the IL from synthesis $[25,26]$. It is possible that the vapour-deposited IL contained impurities, but we believe it is more likely that the contamination of the IL film in this study originates from the background vacuum of the in situ cell. Quantification of the $C$ 1s, $\mathrm{O} 1 \mathrm{~s}$ and $\mathrm{Ti} 2 \mathrm{p}$ regions prior to $\mathrm{IL}$ deposition (on clean $\mathrm{TiO}_{2}$, taken in $\mathrm{UHV}$ ) reveals $(2.3 \pm$ 0.6)\% carbon contamination present on the $\mathrm{TiO}_{2}$ surface (see Table $\mathrm{S} 1$ in the $\mathrm{SI}$ ). The nature of the carbon contamination is not clear (i.e. whether it is flat coverage, island-like growth, etc.), but the presence of carbon prior to IL deposition could explain the strength of the alkyl chain signal in the C 1 s region. Deyko et al [27] studied the influence of carbon coverage on the growth mechanisms of 1-ethyl-3-methylimidazolium bis(trifluoromethylsulfonyl)imide (or $\left[\mathrm{C}_{1} \mathrm{C}_{1} \mathrm{Im}\right]\left[\mathrm{Tf}_{2} \mathrm{~N}\right]$ ) on mica. They found that, on mica surfaces with minimal carbon coverage, the IL demonstrated 3D growth in the form of islands at sub-monolayer IL coverage (i.e. complete dewetting of the mica surface). On mica surfaces with partial or complete carbon coverage, the IL demonstrated 2D layer-by-layer growth on the contaminated areas, and 3D growth on the non-contaminated areas (i.e. partial or complete wetting of the mica surface). This illustrates that carbon contamination can play a rather significant role on the growth of ILs on oxide surfaces. The rutile $\mathrm{TiO}_{2}$ used in our study appears to have minimal carbon coverage prior to IL deposition. Therefore, the IL itself (rather than the $\mathrm{TiO}_{2}$ substrate) may have become contaminated when introduced to the in situ cell. One possible way to remove contamination from ILs is through gentle $\mathrm{Ar}^{+}$ sputtering $[23,25]$, but this was not possible with the sample in the in situ cell.

Another noteworthy observation made by Wagstaffe et al [22] is that the IL adsorbed wellordered on the anatase $\mathrm{TiO}_{2}$, which was corroborated by X-ray absorption measurements. Although it cannot be determined whether the IL film in our study has grown in a 2D or 3D configuration with these data alone, it is likely that the IL film is highly ordered by both the $\mathrm{TiO}_{2}$ and vacuum interfaces. Also reported by Wagstaffe and colleagues was that $\left[\mathrm{C}_{4} \mathrm{C}_{1} \mathrm{Im}\right]\left[\mathrm{BF}_{4}\right]$ chemically interacts with $\mathrm{TiO}_{2}$ via the $\mathrm{F}$ in the anion bonding with $\mathrm{Ti}$, possibly at O-vacancy sites [22]. This statement is supported in the literature by a peak in the F 1s region, with a BE consistent with that of Ti-F bond formation. Because the IL layer studied was approximately a monolayer, this peak was the majority signal in the $\mathrm{F} 1 \mathrm{~s}$ region. $\mathrm{A}$ 
similar peak has been observed in the F 1s region in our study (see Figure S4 in the SI), which we also attribute to F-Ti bonding. Since it is only the first IL layer that bonds to the $\mathrm{Ti}$ surface, the F-Ti peak in our study makes up a smaller percentage of the F 1s signal than that presented by Wagstaffe et al. This therefore corroborates our assessment of the film thickness in our study.

Table 1. Binding energies and assignments of peaks in $C 1$ s and $O 1 s$ regions (Figures 2 and 3 respectively).

\begin{tabular}{ccc}
\hline Region & $\begin{array}{c}\text { Binding Energy }(\mathrm{eV}) \\
(\mathbf{\mathbf { 0 . 1 }} \mathbf{~ e V})\end{array}$ & Assignment \\
\hline $\mathrm{C}$ 1s & 285.5 & $\mathrm{C}_{1}$, alkyl chain \\
& 286.8 & $\mathrm{C}_{2}$, imidazolium \\
& 287.0 & $\mathrm{C}_{3}$, imidazolium \\
& 287.9 & $\mathrm{C}_{4}$, imidazolium \\
\hline $\mathrm{O} 1 \mathrm{~s}$ & 530.2 & $\mathrm{TiO}_{2}$ substrate \\
& 531.5 & Hydroxyl $(\mathrm{Ti}-\mathrm{OH})$ \\
& 533.0 & Hydroxyl $(\mathrm{C}-\mathrm{OH})$ \\
& 533.3 & Adsorbed $\mathrm{H}_{2} \mathrm{O}$ \\
& 535.9 & Gas-phase $\mathrm{H}_{2} \mathrm{O}$ \\
\hline
\end{tabular}

Upon exposure to water, the contribution from the imidazolium ring increases relative to the contribution from the alkyl chain. This indicates a rearrangement of the cations at the surface of the IL, where the imidazolium ring becomes more prominent. We suggest that water adsorbed on the IL causes the cations to rearrange such that the imidazolium ring (the hydrophilic part) is orientated toward the adsorbed water, and the hydrophobic alkyl chain orientates away from the adsorbed water. This water-induced rearrangement of the surface ions could be explained by a dipole-dipole interaction between the imidazolium ring and water lone pair, an interaction previously proposed for water in the bulk of imidazoliumbased ILs and water [28]. In addition, the concentrations of $\mathrm{C}, \mathrm{N}$ and $\mathrm{F}$ have been calculated for the regions before exposure to water and at PS 1 (as the reordering was most prevalent at this stage than at $70 \% \mathrm{RH}$ ) and compared. The concentrations were calculated using the total area of each region (see Table S2 in SI). At PS 1, there is a decrease in the concentration of $\mathrm{C}$ and an increase in the concentration of $\mathrm{N}$ and $\mathrm{F}$. In each case, the concentration decrease/increase is beyond the range of the uncertainty boundaries calculated for the regime before water exposure. This change in composition of the surface further reiterates the idea that the charged parts of the IL, i.e. the anion and the charged 
head of the cation, become more prominent at the IL/water interface than at the IL/vacuum interface. Previous work into the surface interactions between water and ILs by Deyko and Jones [29] suggest that water present on the surface of the analogous $\left[C_{8} C_{1} \mid m\right]\left[B F_{4}\right]$ experiences greater interaction with itself than with the IL surface, behaving as though it were adsorbed on a hydrophobic surface. While this may be consistent with our proposition of water adsorbing on the surface of the IL, the system used by Deyko and Jones had been cooled prior to measurements, so was in fact a glassy solid rather than a liquid film. As water vapour is removed from the in situ cell, the shape of the $C 1 \mathrm{~s}$ peak begins to change again (see Figure 2(c)). The contribution from the alkyl chain now increases relative to the contribution from the imidazolium ring, and the $C 1$ s region begins to resemble the shape of the region prior to water exposure, but the data does not show a complete reversal. This indicates that the ions at the surface begin to return to their original structure as the pressure in the cell returns to high vacuum.
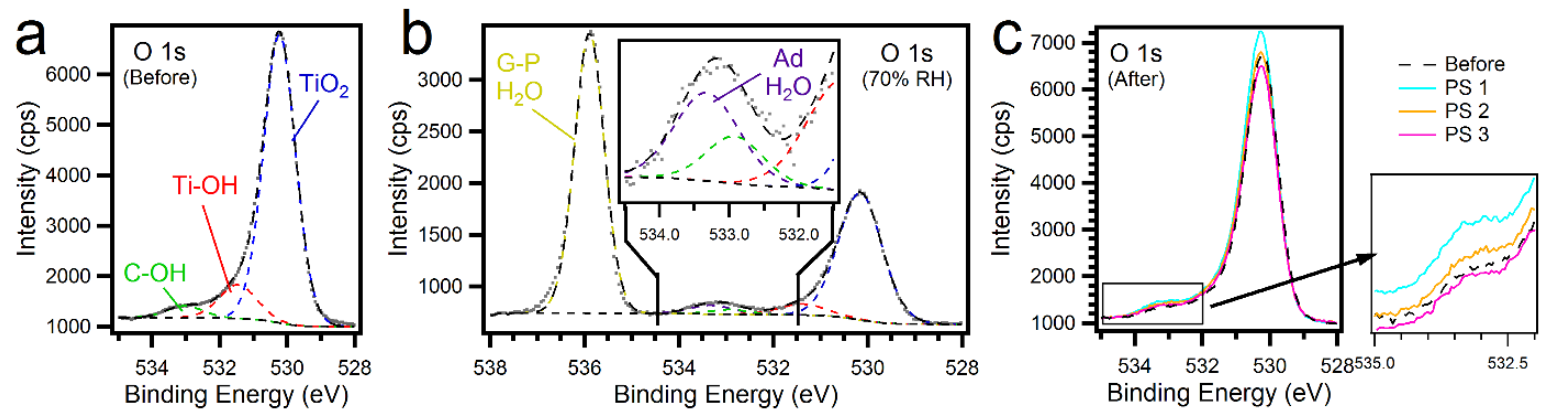

Figure 3. (a) $O$ 1s spectrum before exposure to water, (b) $O$ 1s spectrum at $70 \% R H$, and (c) O1s spectrum from PS 1 to PS 3, together with the pre-water 01 s spectrum.

Figures $3(\mathrm{a})$ and $3(\mathrm{~b})$ show the $\mathrm{O} 1 \mathrm{~s}$ spectrum for the $\mathrm{IL} /$ rutile $\mathrm{TiO}_{2}$ sample before and during exposure to water. Before exposure to water, the region can be fitted with three distinct component peaks. At the lower $\mathrm{BE}$ edge, the peak at $530.2 \mathrm{eV}$ is assigned to the $\mathrm{TiO}_{2}$ lattice oxygen peak [30]. Numerous hydroxyl species can manifest peaks at higher binding energies than the lattice $\mathrm{O}$, including $\mathrm{C}-\mathrm{OH}$ groups [31] and bridging hydroxyls on the rutile $\mathrm{TiO}_{2}(110)$ surface [32], some of which can arise from water in the background vacuum even at high vacuum pressures [33]. Thus, the peaks at $531.5 \mathrm{eV}$ and $533.0 \mathrm{eV}$ are assigned as Ti-OH and $\mathrm{C}-\mathrm{OH}$ species, respectively. 
Upon exposure to water, two new peaks appear at the higher BE edge of the $\mathrm{O} 1 \mathrm{~s}$ spectrum. The peak at $535.9 \mathrm{eV}$ is attributed to gas-phase water, i.e. water vapour surrounding the sample $[34,35]$. The peak at $533.3 \mathrm{eV}(0.2 \mathrm{eV}$ higher $\mathrm{BE}$ than that arising from $\mathrm{C}-\mathrm{OH})$, has been assigned to molecular water adsorbed on the IL film [36, 37]. Although the peaks assigned to hydroxyl species and molecular water are close in $\mathrm{BE}$, two separate peaks were needed to properly fit the spectrum. Furthermore, in situ XPS measurements were previously taken for the same IL on anatase $\mathrm{TiO}_{2}$ (101), but with non-rastered measurements and at a lower RH (see SI for further details). While the data has not been included here due to beam damage, the peak assigned to molecular adsorbed water is more prominent in the $\mathrm{O} 1 \mathrm{~s}$ spectrum due to less attenuation of the signal by the gas-phase water peak (see Figure $\mathrm{S} 2$ in the $\mathrm{SI}$ ). The $\mathrm{O} 1 \mathrm{~s}$ region from those measurements further support the $\mathrm{BE}$ assignment of molecular adsorbed water. All $\mathrm{O}$ 1s peak assignments are displayed in Table 1. When water is evacuated from the in situ cell, the gas-phase water peak disappears whereas the adsorbed water peak is present until the final scan (which was recorded at a background pressure of $\leq 1 \times 10^{-7} \mathrm{mbar}$ ). While the corresponding changes in the $01 \mathrm{~s}$ region are small, they can be seen in the raw data presented in Figure 3c. The prolonged presence of the molecular water peak through PS 1 and 2 indicates water becomes trapped on top of the IL layers for some time. Furthermore, this indicates that the ultrathin IL deposition can stabilise a small amount of water at its surface even in UHV for a period of time.

The ordering at the topmost surface undoubtedly plays a role in the sorption mechanics of ILs, but questions remain as to what kind of interactions occur at the IL/water interface. Rivera-Rubero et al [19] used sum-frequency generation (SFG) spectroscopy, to determine how the presence of water affects the surface ordering of imidazolium-based RTILs. They suggest that the surfaces of hydrophobic (water-immiscible) RTILs are more affected by the addition of water than those of hydrophilic (water-miscible) RTILs. They propose that, in the bulk of the hydrophilic IL, the water molecules are stabilised by intermolecular interactions, such as hydrogen bonding and dipole-dipole forces. In the SFG study, water was allowed to stabilise in a bulk IL, so the interactions and adsorption mechanisms at the IL/water interface were not studied directly. Our study, using an ultrathin film rather than bulk IL, shows that the cations of the water-miscible $\left[C_{4} C_{1} I m\right]\left[B_{4}\right]$ experience an interaction with water molecules at the IL/water interface, possibly through hydrogen bonding and dipole- 
dipole forces with the imidazolium groups. However, there appears to be no reaction with the imidazolium $\mathrm{N}$ atoms (see Figure S3). The interaction appears instead to influence a reorganisation of the molecules at the IL surface, where the imidazolium ring becomes more prominent. An in situ XPS study carried out by Broderick et al [35] investigated the interactions between water and a different water-miscible IL with the same cation. They also suggest that a rearrangement of ions occurs, but rather alkyl chains become more prevalent in the IL/water interfacial region at a water mole fraction of 0.6. However, the system in question was arguably a bulk film, able to absorb and stabilise a relatively large quantity of water in the bulk liquid. Numerous theoretical studies have been conducted into the interactions between $\left[C_{4} C_{1} / m\right]\left[B F_{4}\right][38,39]$, and many of its analogues $[40,41]$, and while local structuring within the bulk liquid has been considered carefully, few have probed the structure and interactions that take place at the IL/water interface upon adsorption.

We propose that the $\left[\mathrm{C}_{4} \mathrm{C}_{1} \mid \mathrm{m}\right]\left[\mathrm{BF}_{4}\right]$ deposition investigated here was sufficiently thin to not have allowed the water molecules at the interface to be absorbed and stabilise between the layers. In a recent study by Buckley et al [42] of the interactions with water and $\left[\mathrm{C}_{8} \mathrm{C}_{1} \mid \mathrm{m}\right]\left[\mathrm{BF}_{4}\right]$, it was found that more than 68 water molecules could be stabilised per IL pair due to long-range interactions with IL ions. This finding supports the idea that water is interacting with, and possibly even being stabilised by, the ultrathin IL film examined here. However, the ability for an IL thin film to adsorb water for a significant period may have a negative impact on IL thin film catalysis applications (such as SILP and SCILL). If the surface structure determines how gases are ad/absorbed into ILS, the presence of water could therefore alter the surface ordering of the IL thin films in these systems. This could then inhibit the reaction kinetics through inhibition of sorption of gaseous reactants and products. As a result, this could diminish the reaction rate and furthermore, diminish the efficiency of these systems.

\section{Conclusion}

Water-induced reordering in an ultrathin film of the IL $\left[C_{4} C_{1} I m\right]\left[B F_{4}\right]$ has been observed using in situ X-ray photoelectron spectroscopy. The results indicate that water is adsorbed on the IL surface, involving an interaction between water and the cations, which leads to a 
reorganisation of the ions at the surface. Water initially remains trapped on the IL surface even as water vapour is pumped out of the in situ cell. The water eventually desorbs when the cell has been under UHV for some time. The combination of water-induced reordering of the ions at the IL surface and the prolonged presence of molecular water under vacuum conditions could have negative implications for IL thin film catalysis. This insight into the behaviour at the interface provides some understanding of the interaction of water with ILS under realistic conditions, and provides a basis for understanding adsorption and absorption mechanisms found in SCILL/SILP catalysis and gas capture/separation applications.

\section{$\underline{\text { References }}$}

[1] W.M. Liu, C.F. Ye, Q.Y. Gong, H.Z. Wang, P. Wang, Tribology Letters, 13 (2002) 81-85.

[2] S. Watanabe, K. Takiwatari, M. Nakano, K. Miyake, R. Tsuboi, S. Sasaki, Tribology Letters, 51 (2013) 227-234.

[3] E.D. Bates, R.D. Mayton, I. Ntai, J.H. Davis, Journal of the American Chemical Society, 124 (2002) 926-927.

[4] S. Raeissi, C.J. Peters, Green Chem., 11 (2009) 185-192.

[5] G.E. Romanos, L.F. Zubeir, V. Likodimos, P. Falaras, M.C. Kroon, B. liev, G. Adamova, T.J.S. Schubert, J. Phys. Chem. B, 117 (2013) 12234-12251.

[6] J. Dupont, R.F. de Souza, P.A. Suarez, Chemical Reviews, 102 (2002) 3667-3692.

[7] D. Zhao, M. Wu, Y. Kou, E. Min, Catalysis Today, 74 (2002) 157-189.

[8] T. Cremer, M. Stark, A. Deyko, H.-P. Steinrück, F. Maier, Langmuir, 27 (2011) 3662-3671.

[9] H.-P. Steinrück, Physical Chemistry Chemical Physics, 14 (2012) 5010-5029.

[10] C.P. Mehnert, R.A. Cook, N.C. Dispenziere, M. Afeworki, Journal of the American Chemical Society, 124 (2002) 12932-12933.

[11] J. Arras, M. Steffan, Y. Shayeghi, D. Ruppert, P. Claus, Green Chem., 11 (2009) 716-723.

[12] T. Cremer, L. Wibmer, S.K. Calderón, A. Deyko, F. Maier, H.-P. Steinrück, Physical Chemistry Chemical Physics, 14 (2012) 5153-5163.

[13] T.J. Gannon, G. Law, P.R. Watson, A.J. Carmichael, K.R. Seddon, Langmuir, 15 (1999) 8429-8434.

[14] V. Lockett, R. Sedev, C. Bassell, J. Ralston, Physical Chemistry Chemical Physics, 10 (2008) 1330-1335. 
[15] Y. Jeon, J. Sung, W. Bu, D. Vaknin, Y. Ouchi, D. Kim, Journal of Physical Chemistry C, 112 (2008) 19649-19654.

[16] R.M. Lynden-Bell, M. Del Popolo, Physical Chemistry Chemical Physics, 8 (2006) 949954.

[17] Y. Lauw, M.D. Horne, T. Rodopoulos, N.A.S. Webster, B. Minofar, A. Nelson, Physical Chemistry Chemical Physics, 11 (2009) 11507-11514.

[18] H. Xu, Z. Han, D.J. Zhang, J.H. Zhan, ACS Appl. Mater. Interfaces, 4 (2012) 6646-6653.

[19] S. Rivera-Rubero, S. Baldelli, Journal of the American Chemical Society, 126 (2004) 11788-11789.

[20] L.E. Ficke, J.F. Brennecke, J. Phys. Chem. B, 114 (2010) 10496-10501.

[21] C. Ridings, V. Lockett, G. Andersson, Physical Chemistry Chemical Physics, 13 (2011) 21301-21307.

[22] M. Wagstaffe, M.J. Jackman, K.L. Syres, A. Generalov, A.G. Thomas, ChemPhysChem, 17 (2016) 3430-3434.

[23] E.F. Smith, F.J. Rutten, I.J. Villar-Garcia, D. Briggs, P. Licence, Langmuir, 22 (2006) 93869392.

[24] H. Hashimoto, A. Ohno, K. Nakajima, M. Suzuki, H. Tsuji, K. Kimura, Surface Science, 604 (2010) 464-469.

[25] K. Lovelock, C. Kolbeck, T. Cremer, N. Paape, P. Schulz, P. Wasserscheid, F. Maier, H.-P. Steinruck, The Journal of Physical Chemistry B, 113 (2009) 2854-2864.

[26] K.R.J. Lovelock, E.F. Smith, A. Deyko, I.J. Villar-Garcia, P. Licence, R.G. Jones, Chem. Commun., (2007) 4866-4868.

[27] A. Deyko, T. Cremer, F. Rietzler, S. Perkin, L. Crowhurst, T. Welton, H.-P. Steinrück, F. Maier, The Journal of Physical Chemistry C, 117 (2013) 5101-5111.

[28] M. Reichelt, T. Hammer, H. Morgner, Surface Science, 605 (2011) 1402-1411.

[29] A. Deyko, R.G. Jones, Faraday Discussions, 154 (2012) 265-288.

[30] K.L. Syres, A.G. Thomas, W.R. Flavell, B.F. Spencer, F. Bondino, M. Malvestuto, A. Preobrajenski, M. Grätzel, The Journal of Physical Chemistry C, 116 (2012) 23515-23525.

[31] L.-Q. Wang, D.R. Baer, M.H. Engelhard, A.N. Shultz, Surface Science, 344 (1995) 237250.

[32] M.B. Hugenschmidt, L. Gamble, C.T. Campbell, Surface Science, 302 (1994) 329-340. 
[33] A.C. Papageorgiou, G. Cabailh, Q. Chen, A. Resta, E. Lundgren, J.N. Andersen, G. Thornton, Journal of Physical Chemistry C, 111 (2007) 7704-7710.

[34] S. Yamamoto, H. Bluhm, K. Andersson, G. Ketteler, H. Ogasawara, M. Salmeron, A. Nilsson, Journal of Physics-Condensed Matter, 20 (2008) 184025.

[35] A. Broderick, Y. Khalifa, M.B. Shiflett, J.T. Newberg, The Journal of Physical Chemistry C, 121 (2017) 7337-7343.

[36] L. Walle, A. Borg, P. Uvdal, A. Sandell, Physical Review B, 86 (2012) 205415.

[37] G. Ketteler, S. Yamamoto, H. Bluhm, K. Andersson, D.E. Starr, D.F. Ogletree, H. Ogasawara, A. Nilsson, M. Salmeron, The Journal of Physical Chemistry C, 111 (2007) 82788282.

[38] J. Carrete, T. Mendez-Morales, O. Cabeza, R.M. Lynden-Bell, L.J. Gallego, L.M. Varela, The Journal of Physical Chemistry B, 116 (2012) 5941-5950.

[39] J. Gao, N.J. Wagner, Langmuir, 32 (2016) 5078-5084.

[40] S. Feng, G.A. Voth, Fluid Phase Equilibria, 294 (2010) 148-156.

[41] T. Méndez-Morales, J. Carrete, O. Cabeza, L.J. Gallego, L.M. Varela, The Journal of Physical Chemistry B, 115 (2011) 6995-7008.

[42] M. Buckley, K.L. Syres, R.G. Jones, Faraday Discussions, 206 (2017) 475-495. 